\title{
BMJ Open Neighbourhood characteristics and cumulative biological risk: evidence from the Jamaica Health and Lifestyle Survey 2008: a cross-sectional study
}

\author{
Colette Andrea Cunningham-Myrie, ${ }^{1}$ Emily Mabile, ${ }^{2}$ Ishtar Govia, ${ }^{3}$ \\ Novie O Younger, ${ }^{3}$ Marshall Kerr Tulloch-Reid, ${ }^{3}$ Shelly McFarlane, ${ }^{3}$ \\ Damian Francis, ${ }^{3}$ Georgiana Gordon-Strachan, ${ }^{3}$ Rainford Wilks, ${ }^{3}$ \\ Lisa-Gaye Greene, ${ }^{4}$ Parris Lyew-Ayee, ${ }^{4}$ Katherine P Theall ${ }^{5}$
}

To cite: CunninghamMyrie CA, Mabile E, Govia I, et al. Neighbourhood characteristics and cumulative biological risk: evidence from the Jamaica Health and Lifestyle Survey 2008: a crosssectional study. BMJ Open 2018;8:e021952. doi:10.1136/ bmjopen-2018-021952

- Prepublication history for this paper is available online. To view these files, please visit the journal online (http://dx.doi. org/10.1136/bmjopen-2018021952).

Received 26 January 2018 Revised 11 August 2018 Accepted 4 October 2018
Check for updates

(C) Author(s) (or their employer(s)) 2018. Re-use permitted under CC BY-NC. No commercial re-use. See rights and permissions. Published by BMJ.

For numbered affiliations see end of article.

Correspondence to Dr Katherine P Theall; ktheall@tulane.edu

\section{ABSTRACT}

Objective To examine whether neighbourhood characteristics are associated with cumulative biological risk (CBR) and sex differences in CBR in a nationally representative sample in Jamaica, a small island developing country with increasing prevalence of noncommunicable diseases (NCDs).

Design Cross-sectional study

Setting A population-based cross-sectional survey, the Jamaica Health and Lifestyle Survey 2008 (JHLS II) recruited persons at their homes over a 4 month period from all 14 parishes and 113 neighbourhoods defined as enumeration districts (EDs).

Participants 2544 persons aged 15-74 years old from the 2008 Jamaica Health and Lifestyle Survey (JHLS II), who completed interviewer-administered questionnaires and had biomarkers assessed, and whose home addresses could be reliably geocoded.

Primary outcome A summary measure CBR was created using seven markers-systolic and diastolic blood pressure readings, waist circumference, body mass index, total cholesterol, fasting blood glucose levels and selfreported asthma. Weighted multilevel models examined clustering, using the intraclass correlation coefficient (ICC), of CBR across neighbourhoods and the impact of neighbourhood characteristics (recreational space availability and neighbourhood disorder) on CBR.

Results Women had significantly higher mean CBR scores than men across all age groups. There was significant clustering of CBR by ED, and among women versus men (ICC: $\mathrm{F}=6.9 \%, \mathrm{M}=0.7 \%$ ). Women living in more disordered neighbourhoods were $26 \%$ more likely to have high CBR as those in less disordered ones $(\mathrm{aOR}=1.26,95 \% \mathrm{Cl}=1.08$ to $1.47 ; \mathrm{p}<0.05$ ). Individuals living in EDs with greater recreational space availability were $25 \%$ less likely to have a high CBR ( $a 0 R=0.75,95 \%$ $\mathrm{Cl}=0.64$ to $0.90 ; \mathrm{p}<0.05)$.

Conclusions Policy-makers in Jamaica should pay greater attention to neighbourhood factors such as recreational space availability and neighbourhood disorder that may contribute to CBR in any effort to curtail the epidemic of NCDs.

\section{Strengths and limitations of this study}

- This study provides a large sample size representative of Jamaicans aged 15 to 74 years.

- The study examines the role of neighbourhood context, including factors beyond socioeconomic status, on biological stress in a middle-income country context.

- The study included only seven markers to assess cumulative biological risk (CBR) and had no neuroendocrine or immune biomarkers based on data unavailability.

- The neighbourhood was defined as an enumeration district (ED), many of which are heterogeneous, making it possible that important geographic effects may have been misclassified or not captured.

- Neighbourhood characteristics were subjectively assessed by interviewers, increasing the possibility of information bias.

\section{INTRODUCTION}

The global epidemic of the non-communicable diseases (NCDs) has resulted in continued research efforts to understand and ameliorate the antecedents, and there is accumulating evidence suggesting that cumulative biological risk (CBR) is associated with NCDs and may be an early warning sign for later negative health outcomes. ${ }^{1}$ CBR is often operationalised as allostatic load (AL), defined as the cumulative wear and tear on physiological systems and organs due to chronic stress. ${ }^{2-4}$ It has been posited as a key mechanism in the association between early life adversity and later health outcomes, including illness and mortality, ${ }^{5}$ and is an important pathway that may be a link to socioeconomic and racial/ethnic health disparities. ${ }^{4}$ The original operationalisation of AL involved a countbased index from 10 markers of multisystem 
biological dysregulation ${ }^{67}$ that fall under two main categories: (a) primary mediators, or substances the body releases in response to stress and disruption in hypothalamic-pituitary-adrenocortical and sympathetic-adrenocortical activity such as norepinephrine and cortisol and (b) secondary outcomes such as elevated blood pressure and body mass index (BMI), which are effects that result from the actions of the primary mediators. ${ }^{8}{ }^{9}$ From a population health perspective, it is important to identify potential factors amenable to change that may impact CBR on a larger scale.

The neighbourhood environment may play a key direct and indirect role in shaping CBR through dysregulation of the physiologic and stress response systems and potential behavioural and health outcomes, ${ }^{10-12}$ as well as in the production of racial and socioeconomic disparities in outcomes. ${ }^{13}$ Neighbourhoods may impact CBR through their impact on health behaviours, for example, neighbourhood safety has been linked to a lower likelihood of engaging in physical activity and an increased risk of obesity. ${ }^{14-16}$ Social conditions such as high crime and neighbourhood disorder, as well as poor built environments (eg, inadequate access to healthy foods and physical and recreational activity spaces) are all too common in socioeconomically disadvantaged neighbourhoods. ${ }^{17}$

Beyond socioeconomic status, however, few studies have examined additional neighbourhood stressors and their impact on CBR or markers of CBR. Neighbourhood disorder, characterised by high levels of violence, low social control and poor built environments, ${ }^{18}$ may be an important factor in the production of stress and CBR, even above and beyond the impact on health behaviours. Neighbourhood disorder has been linked to markers of biological stress in both children ${ }^{19}$ and adults. ${ }^{20}$ It is also important to examine specific aspects of disordered neighbourhoods, such as built environments like physical activity or recreational space availability. Availability of spaces to be physically active has been linked to NCDs like obesity ${ }^{21} 22$ and NCD risk factors. ${ }^{23}$ Neighbourhood conditions and their association with CBR, however, have not been examined in developing country contexts.

The vulnerability to social environmental stress, its impact on CBR and subsequent health risk may also differ according to sex and race. Few studies exist comparing sex differences in CBR, and whatever sex differences exist may vary from country to country. For example, in a nationally representative study in USA including individuals aged 17 years and older, women had a higher AL than men, with larger differences after menopause. ${ }^{24}$ However, among the Japanese aged 55 to 89 years, women had lower AL than men. ${ }^{25}$ Another study of mostly White workers aged 27 to 65 years of age in Montreal Canada, suggested that sex differences in AL may be more closely related to gender roles than biological sex, per se. ${ }^{26}$ Empirical evidence for sex differences in CBR or across individual systems remains limited, ${ }^{24-29}$ particularly in a developing country context. Furthermore, the differential effect of neighbourhood conditions on CBR by sex or gender has been seldom investigated. This is despite existing evidence of a differential effect of the neighbourhood environment on women versus men, due to a hypothesised increased susceptibility and/or exposure of women to neighbourhood effects. ${ }^{30}$ Among adults, research has shown that women subjectively experience more stress than men and consistently report more physical and somatoform symptoms, and show higher stress vulnerability. ${ }^{31-34}$ With respect to race, in the USA, Blacks have been shown to have higher rates of CBR or AL, ${ }^{4} 3$ live in more deprived neighbourhoods, ${ }^{35}$ compared with Whites, and Black women have shown the most consistently elevated levels of AL across age groups. ${ }^{36}$

Neighbourhood socioeconomic status, ${ }^{10} 13$ and conditions have been positively associated with the accumulation of biological risk in developed countries, ${ }^{37} 38$ but limited work has been done in developing countries. Jamaica provides a unique environment for examining neighbourhood influences on CBR and differences between Black women and men in a developing country, given the island has a predominantly $(94 \%)$ Black population with increasing prevalence of NCDs. ${ }^{39}$ The epidemiological profile of NCDs in Jamaica mirrors that of many small island developing states having undergone an epidemiological transition and are struggling to deal with the high cost of NCD management. ${ }^{40} 41$ Furthermore, increasing levels of poverty in the country, ${ }^{42}$ coupled with high levels of neighbourhood-level social stratification and potential consequences of stratification (eg, crime, discrimination) in Jamaica, ${ }^{43}$ may be contributing significantly to rates of NCD and risk factors like CBR. However, few studies have examined more distal exposures, with the exception of a handful focused on mental health outcomes ${ }^{44} 45$ and our previous secondary analysis of the national Jamaica Health and Lifestyle Survey (JHLS II),${ }^{46}$ which revealed that differences in obesity-related outcomes may be partially explained by characteristics of the neighbourhood environment. We found an impact of neighbourhood infrastructure on overweight/ obesity that differed by sex, with a significant association in men but not women.

Within the contemporary Jamaican and US contexts, there are key indicators of social stratification that set men and women apart (eg, single parenthood, household headship and poverty) and that are related to differences in the prevalence and incidence of physical and mental health outcomes. Examination of differences within otherwise homogeneous geographic or social communities provides a more organic understanding of the theories of fundamental cause in terms of 'spatial externalities' (eg, economic policies made at the community level), which may allow for better design of effective population level interventions. ${ }^{47}{ }^{48}$ In the proposed study, we aimed to examine the production of biological stress in a seemingly homogeneous racial population and how such structural factors may be embodied, ${ }^{49}$ providing a comprehensive socio-ecological framework that will inform treatment and prevention efforts in middle-income countries like 
Jamaica as well as those aimed at reducing disparities in the USA by targeting differences within groups. ${ }^{37} 3846$

Through a secondary analysis of the JHLS II dataset, we examined the relation between neighbourhood conditions-specifically, neighbourhood disorder and availability of recreational spaces-and CBR in Jamaica, as well as differences by sex. We hypothesised that Jamaican females would have higher CBR than their male counterparts and that CBR would be associated with neighbourhood environments, although differentially by sex. We have chosen to use the terminology CBR instead of AL, given our survey data does not include measures of primary stress mediators.

\section{MATERIALS AND METHODS}

\section{Study design and population}

Data were obtained from the JHLS II dataset, a nationally representative cross-sectional survey conducted among 2897 individuals aged 15-74 years old between November 2007 and March 2008. The JHLS II captured health information through (i) an interviewer-administered survey, (ii) anthropometry and (iii) bio-specimens for blood cholesterol and glucose via the finger-prick method utilising point-of-care instruments for testing. The field team was trained in interview techniques and all were certified to conduct anthropometry and other biomedical assessments. Recruitment was conducted by random selection of clusters (enumeration districts) using a probability proportional to the size of the population within all parishes in Jamaica. Within each cluster, every 10th household was systematically selected from a randomly selected starting point, with a single individual being chosen to represent each household. Of those sampled, 353 participants did not have complete biomedical data and were excluded from the analyses, leaving a final sample of 2544 individuals analysed. Further details on sampling methods and procedures followed to collect biomedical measures are found in the technical report. ${ }^{39}$

\section{Patient and public involvement}

Study participants were generally residents of communities and no patients were involved in the study. The study participants were not involved in the design, recruitment or the conduct of the study. The study findings will be disseminated to the Ministry of Health, Jamaica, and general public, including the study participants.

\section{Measures}

\section{Individual-level measures}

The primary outcome CBR was based on a summary score from seven markers based on availability of data. Markers included systolic blood pressure (SBP) and diastolic blood pressure (DBP), waist circumference (WC), BMI, total cholesterol (TC) levels and fasting blood glucose (FBG) levels. Given the absence of an inflammatory marker in the data set, self-reported asthma was added, given that it is an inflammatory condition.$^{50}$ It has been used in previous studies assessing CBR. ${ }^{37}$

Each marker had a clinically defined age-specific cut-off for high risk. Adult cut-off values were: $>130 \mathrm{~mm} \mathrm{Hg}$ for SBP, $>85 \mathrm{~mm} \mathrm{Hg}$ for DBP, $\geq 94 \mathrm{~cm}$ for male and $\geq 80 \mathrm{~cm}$ for female WC, ${ }^{36} \geq 25 \mathrm{~kg} / \mathrm{m}^{2}$ for BMI, $>6.2 \mathrm{mM} / \mathrm{L}$ for TC levels $^{51}$ and $\geq 110 \mathrm{mg} / \mathrm{dL}(6.1 \mathrm{mmol} / \mathrm{L})$ for FBG levels. ${ }^{52}$ CBR was examined as both a continuous and a dichotomous variable. High CBR was defined as at least one SD above the mean score and a dichotomous score assigned for high or low risk (1 or 0 respectively). Scores were summed to create the total CBR score with a possible maximum score of 7 (self-reported asthma included). Youth $(<18$ years) were defined as being 'at risk' with regard to each biomarker if their value was greater than one SD above the mean for their age and sex or if they had a value at/above the adult cut-off value. The exception was SBP and DBP, with high risk cut-points defined as being greater than or equal to the 94th percentile for age, sex and BMI. ${ }^{53}$

Covariates such as age, sex, education level $(<$ than vs $\geq$ high school) and smoking status (currently smoke any form of tobacco) were also examined. Further details on how these variables were assessed can be found in the technical report. ${ }^{39}$

\section{Household measures}

The number of possessions in a household from a list of 20 items (including car ownership) was used as a proxy for reflecting socioeconomic status (SES). Household crowding was also examined as a potential confounder, defined as both more than one person per habitable room as well as the average number of individuals per habitable room. A complete list is documented in the technical report. ${ }^{39}$

\section{Neighbourhood-level measures}

The neighbourhood was defined as the enumeration district (ED) a geographical unit consisting of up to 400 dwellings. Home addresses were geographically linked to EDs within each parish using ArcGIS V.10.1 (ESRI, Redlands, CA, USA). A total of 113 EDs were analysed, with an average of 15 individuals per ED.

Interviewers' perceptions were aggregated for each subject/household and then to the ED level to obtain markers at the neighbourhood level. An index of neighbourhood disorder was created based on a composite score of the interviewers' perception of the condition of the homes, condition of the streets, condition of the yards, the amount of noise and the air quality in the neighbourhoods. Scores for each variable ranged from 1 (excellent) to 4 (poor) and the overall index ranged from 1 to 20, and therefore higher total scores indicated greater neighbourhood disorder. While there are no gold standard measures for neighbourhood disorder, indices representing both social and physical disorder in communities have been widely employed and utilising both self-reported or perceived as well as objective 
measures. ${ }^{19}{ }^{54-56}$ Some have included only markers of physical disorder, as is the case in the present study and is a limitation; however, physical disorder has been closely linked to social disorder but may not necessarily be a marker of social disorder. ${ }^{57-59}$ Nonetheless, physical disorder may contribute to biological stress markers such as CBR, irrespective of social disorder.

Recreational areas/playing fields/open spaces availability in the participant's neighbourhood was also assessed based on the interviewer's perception of (a) the presence of and (b) walking distance to either recreational spaces, playing fields or other open spaces from a participant's home. Scores assigned were 0 (no) and 1 (yes), with a total possible maximum score of 2. Responses where an interviewer indicated an inability to assess or was unsure were excluded from the analysis at the individual level. Eight per cent of respondents were missing data on neighbourhood-level items; however, those excluded did not differ in any way from those included in the analysis. Both disorder and recreational availability were individual-level measures, assessed based on the participant's home and immediate walking area around the home; therefore, missing data was only at the level of the individual and not the $\mathrm{ED}$.

\section{Statistical analysis}

Data were analysed descriptively using SAS complex survey design methods specifying weight, stratum and clustering variables to account for the JHLS sampling procedures when CBR was described in terms of age and sex. Means and proportions were compared using survey-weighted t-tests and the $\chi^{2}$ test respectively. Two-level multilevel models using PROC MIXED or PROC GLIMMIX for the dichotomised CBR were employed to examine clustering of CBR across neighbourhoods and the impact of neighbourhood conditions on CBR. Multilevel models were also weighted for sampling design and survey non-response and regression diagnostics for linear models were conducted prior to the two-level multilevel modelling. We initially ran empty models to determine group-level influences on individual outcomes, often expressed as the intraclass correlation coefficient (ICC) and calculated for our linear model as: $\left(\mathrm{V}_{\mathrm{ED}} / \mathrm{V}_{\mathrm{ED}}+\mathrm{V}_{\text {individual }}\right) \mathrm{X} 100$ where $\mathrm{V}_{\mathrm{ED}}=$ variance between EDs and $\mathrm{V}_{\text {individual }}=\mathrm{variance}$ among individuals within EDs. An ICC at or above 2\% is suggestive of a potential higher level effect (eg, neighbourhood) and worth examining in a multilevel framework. ${ }^{60}$ Since the outcome variable is binary, the ICC was calculated using Snijders formula where $\mathrm{V}_{\text {student }}=\Pi 2 / 3 .^{61} 62$

Modelling was performed in the following steps: (1) examination of empty random intercept models, in which there were no predictors, to determine the extent of clustering of CBR values by neighbourhood, (2) testing the unadjusted associations between the neighbourhood environments and CBR, (3) testing the adjusted association, after accounting for potential confounders and testing potential interaction by sex, (4) test of random slope model, with neighbourhood exposures considered as random effects and (5) final stratified models, controlling for potential confounders. Models were run with and without youth, as well as with and without the unconventional asthma marker to test the stability of findings.

\section{RESULTS}

The weighted sex and age stratified statistics are shown in table 1 . The mean age was approximately 35 years for each sex and $73 \%$ of women had achieved at least high school level of education compared with $69 \%$ for their male counterparts. Significant sex differences were noted for all the individual cardiovascular and metabolic markers with the exception of FBG, with men having greater SBP and DBP and women having higher WC and TC on average. Women had significantly higher mean BMI (mean $=28.50$ vs $24.50, \mathrm{p}<0.05$ ) and significantly higher mean CBR scores than men (2.38 vs $1.68, \mathrm{p}<0.01$ ). No clustering was observed for the inflammatory marker asthma. There were no sex differences in neighbourhood exposures, with similar proportions of men and women having recreation or playing areas in their community and a similar mean neighbourhood disorder score (table 1). Youth comprised approximately $4 \%$ of the participants. There were also significant age differences compared with adults for all the individual cardiovascular and metabolic markers, including mean FBG.

Twenty-two per cent of the sample was considered to have high CBR. Figure 1 presents the total and sex-specific percentages of high CBR scores in 10 year age groups. The group aged 35-44years had the largest percentage (31\%) of high CBR scores with an approximate $20 \%$ difference in high scores between women and men. Sex differences in mean scores tapered off in older and younger age groups but remained significant at all ages.

We observed significant clustering of CBR at the neighbourhood level with an ICC of $4.6 \%$ (figure 2). This suggests that some of the variance observed in CBR may be explained by neighbourhood level factors. Significant clustering with ICC values of over $4.0 \%$ was observed for all other biomarkers except for self-reported asthma and FBG. The highest levels of clustering were seen for both DBP and SBP. Also shown in figure 2 are ICCs by sex and demonstrates the substantial difference in clustering by ED between women and men $(6.9 \%$ vs $0.7 \%)$.

\section{Neighbourhood characteristics and CBR}

Table 2 presents combined and sex-specific results from the multilevel logistic regression models using CBR as a dichotomous outcome. For the combined results (adjusted for age, sex and number of possessions) the likelihood of high CBR was significantly lower among respondents with greater recreational space availability $(\mathrm{aOR}=0.75 ; 95 \% \mathrm{CI}=0.64,0.94 ; \mathrm{p}<0.05)$. Controlling for the other individual level covariates such as smoking, diet or physical activity did not alter the associations and were therefore not included in models. While the overall association between neighbourhood disorder and high CBR 


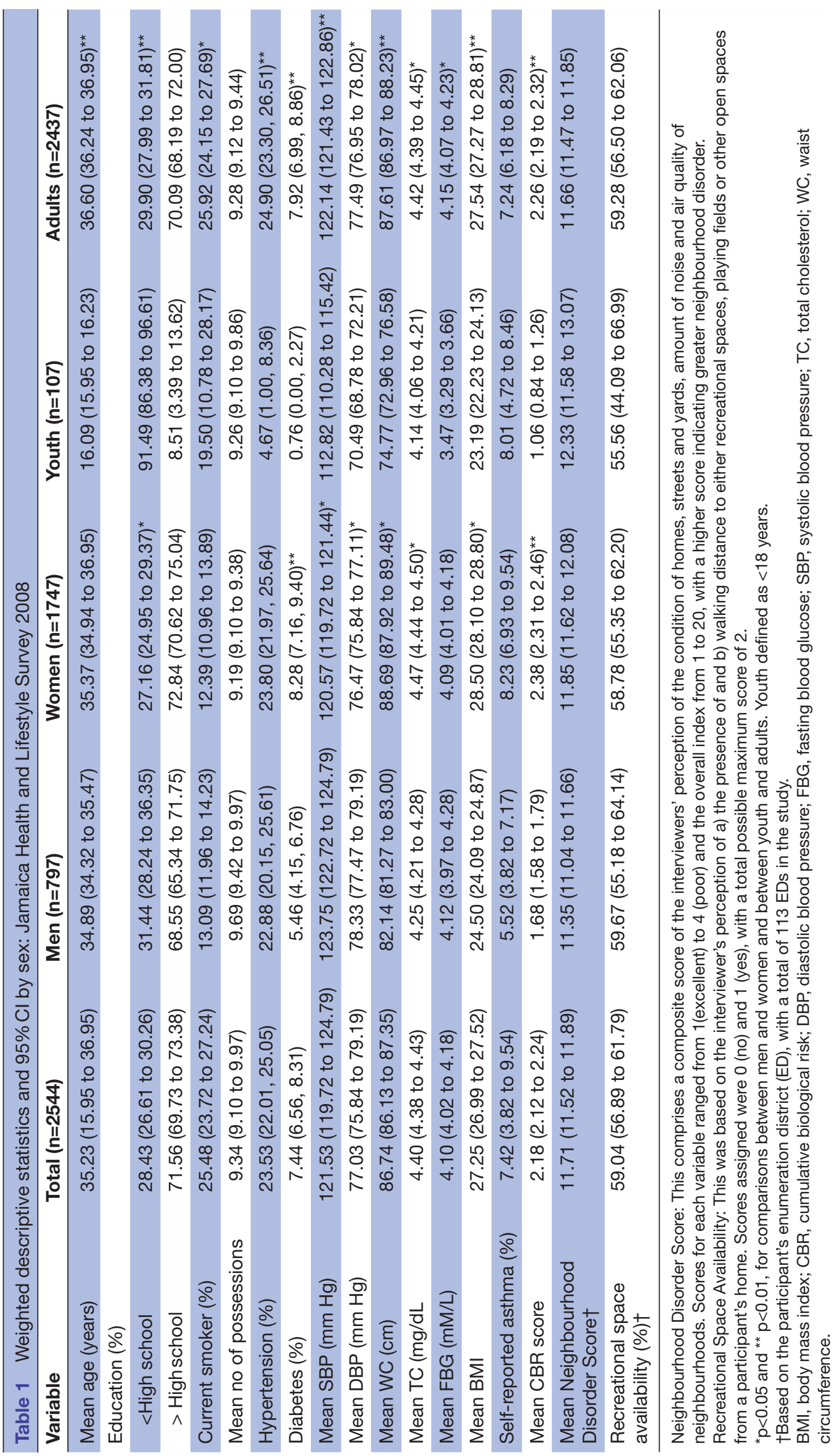




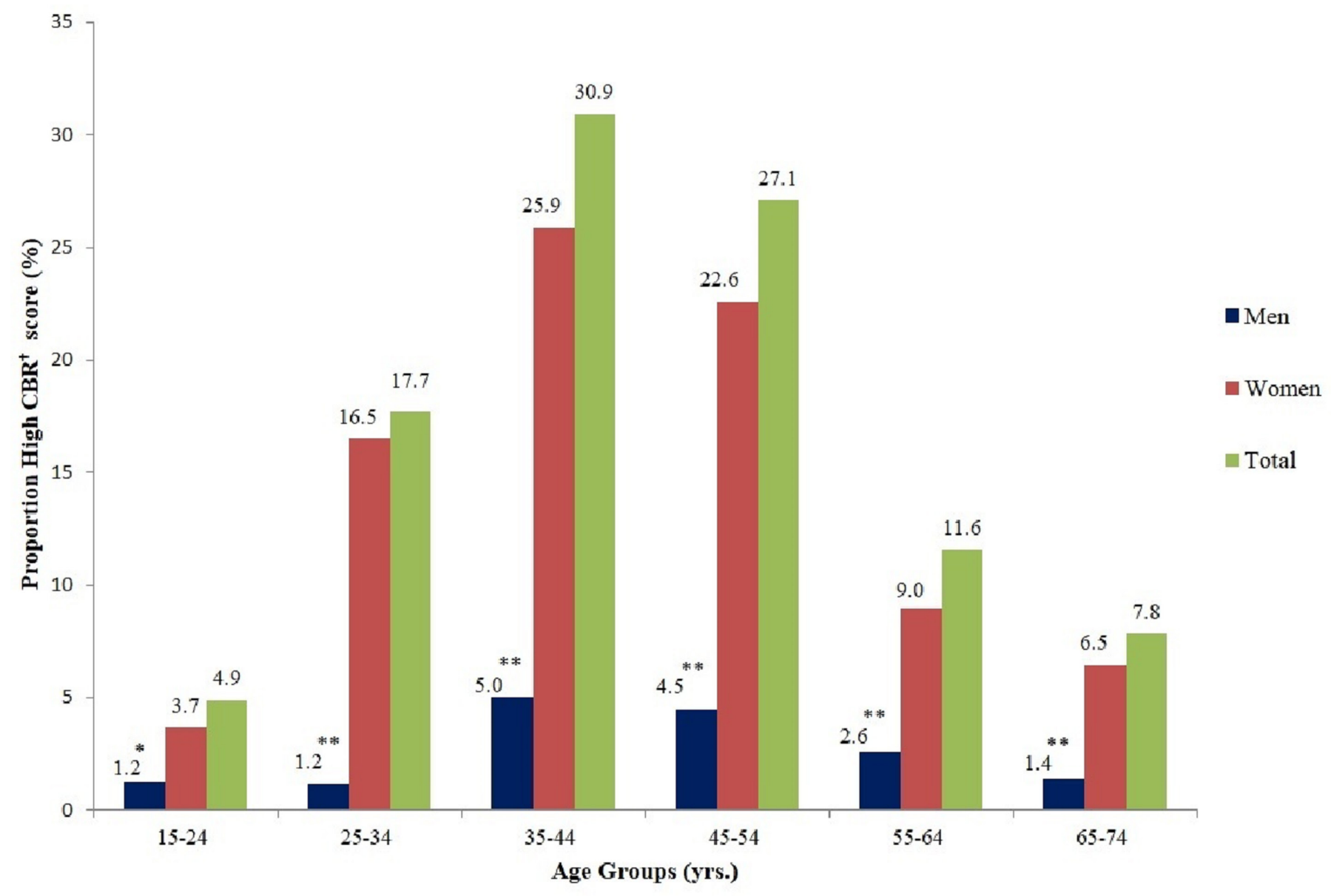

Figure 1 Proportion of high cumulative biological risk (CBR)† score by age and sex. †High CBR was defined as at least 1 SD above the mean score. ${ }^{*} \mathrm{P}<0.01$ and ${ }^{* *} \mathrm{p}<0.001$ comparing sex differences within each age group.

was not statistically significant, significant interaction by sex was observed. Sex-specific results revealed a significant association between neighbourhood disorder score and high $\mathrm{CBR}(\mathrm{OR}=1.26 ; 95 \% \mathrm{CI}=1.08,1.47 ; \mathrm{p}<0.05)$ in women but not for men $(\mathrm{OR}=0.97 ; 95 \% \mathrm{CI}=0.86,1.09)$, with the likelihood of high CBR increasing by $26 \%$ for each unit increase in neighbourhood disorder score among women. Results were consistent when using CBR as a continuous variable.

We observed no statistically significant interaction by sex in the relationship between recreational space availability and high CBR. Inclusion of both neighbourhood exposures and individual level covariates did reduce the ICC overall. All analyses were also run with and without youth included, as well as with and without the unconventional asthma marker and there were no changes in the overall results.

\section{DISCUSSION}

CBR increased with age for both sexes and was significantly higher among women. Higher levels of recreational space availability were associated with less CBR and greater neighbourhood disorder was significantly associated with high CBR for women but not men.
Our findings are consistent with reports elsewhere of an increase in CBR with age, at least up to the sixth decade of life. ${ }^{4263}$ In our study, CBR increased with age for both sexes, and was consistently higher among the women across the life span. This is consistent with studies that have found this sex differential, ${ }^{2564}$ but is a novel contribution to the existing literature given that our study population included women from as young as 15 years old, while the majority of studies examining sex differences in CBR include only older adult women We are unclear if this sex differential reflects genetic and/or gender underpinnings unique to the Jamaican context, or simply differences with unmeasured sample characteristics. Additionally, while our findings align with literature on poorer women's susceptibility to repeated exposures and adaptations to stressors in more developed country contexts, ${ }^{4}$ the scholarship on CBR in developing contexts such as the Caribbean is limited. Studies in Jamaica have documented a strong association between morning salivary cortisol levels and hypertension, ${ }^{65}$ in mothers and their offspring. Future studies examining sex differences in the association between cortisol and other specific neuroendocrine and immune/inflammatory indicators used in the operationalisation of CBR may explain 




Figure 2 Neighbourhood clustering (intraclass correlation coefficient [ICC] \%) of high cumulative biological risk (CBR)* by individual biomarkers ${ }^{\star *}$ and sex. CBR, cumulative biological risk; DBP, diastolic blood pressure; SBP, systolic blood pressure; WC, waist circumference; TC, total cholesterol; FBG, fasting blood glucose; BMI, body mass index. *High CBR was defined as at least one SD above the mean score. ${ }^{*}$ Individual biomarkers were included based on high risk cut-points: Self-reported asthma, DBP > $85 \mathrm{~mm} \mathrm{Hg}$, SBP $>130 \mathrm{~mm} \mathrm{Hg}$, WC $>85 \mathrm{~mm} \mathrm{Hg}, \mathrm{TC}>5.7 \mathrm{mM} / \mathrm{L}, \mathrm{FBG} \geq 110 \mathrm{mg} / \mathrm{dL}$ and BMl $\geq 25 \mathrm{~kg} / \mathrm{m}^{2}$; for youth $<18$ years old high-risk cut-points used were $>$ one SD above the mean for their age and sex or $\geq$ the adult high risk cutpoint value, except for SBP and DBP, with high risk cut-points defined as being greater than or equal to the 94th percentile for age, sex and BMI.

this observed sex differential. We were unable to assess racial disparities given that Jamaicans are predominantly Black. However, studies in the USA have found that Black women exhibit greater CBR than Black men and more so than other racial groups. ${ }^{410}$ This suggests possible epigenetic and/or environmental underpinnings. Our

Table 2 Unadjusted and adjusted OR (95\% Cl) for high CBR*overall and stratified by sex ( $\mathrm{n}=2544)$

\begin{tabular}{|c|c|c|c|c|}
\hline \multirow[b]{2}{*}{ Neighbourhood characteristic } & \multicolumn{2}{|c|}{ Overall CBR $(95 \% \mathrm{Cl})$} & \multicolumn{2}{|c|}{ CBR stratified by sex $(95 \% \mathrm{Cl})$} \\
\hline & Unadjusted & Adjusted $†$ & Women & Men \\
\hline Neighbourhood Disorder Score & 1.00 (0.97 to 1.03$)$ & $1.01(0.98-1.04)$ & $1.26(1.08$ to 1.47$) \ddagger$ & $0.97(0.86-1.09)$ \\
\hline ICC (\%) & 3.10 & 2.46 & 2.83 & 2.20 \\
\hline Recreational space availability & $0.79(0.65$ to 0.95$) \ddagger$ & $0.75(0.64-0.90) \ddagger$ & 0.82 (0.49 to 1.36$)$ & $0.91(0.63-1.29)$ \\
\hline ICC (\%) & 3.20 & 2.54 & 4.80 & 2.09 \\
\hline
\end{tabular}

ICC was calculated as $\left(V_{E D} N_{E D}+V_{\text {individual }}\right) \times 100$ where $V_{E D}=$ variance between EDs and $V_{\text {individual }}=$ variance among individuals within $E D s$. ${ }^{*}$ High CBR was defined as at least one $S D$ above the mean score.

†Adjusted for age, sex, education, no. of possessions, smoking status; stratified by sex, adjusted for age, education and no. of possessions. $\ddagger \mathrm{P}<0.05$.

CBR, cumulative biological risk; ICC, intraclass correlation coefficient. 
analysis had no neuroendocrine markers, and some are recognised to produce differentially higher response to stress in Blacks. ${ }^{66}$

The clustering of CBR across neighbourhoods indicates that some of the variance in CBR may be due to neighbourhood environment, and more so for women. ${ }^{45}$ Findings corroborate those that have reported the stress reducing effects of recreational spaces, ${ }^{67}$ others that have demonstrated an effect of neighbourhood stress on $\mathrm{CBR}^{19} 20$ and add to the work examining the differential impact of such contextual stress by sex. Research has shown that women subjectively experience more stress than men and consistently report more physical and somatoform symptoms and show higher stress vulnerability. ${ }^{31-34}$ Availability of physical activity spaces in neighbourhoods has been associated with better cardiovascular and mental health. ${ }^{68} 69$ The lack of community spaces for physical activity may be a barrier to engaging in physical activity for residents. Neighbourhood disorder may be a marker of more deprived community environments, whereby healthy food access is limited ${ }^{70} 71$ and may lead to higher $\mathrm{CBR} .{ }^{25}$ Disorder and the stress it may induce could also lead to differences in coping, particularly among women. Fernandez $e t a l^{72}$ found that the disengagement coping styles of African American women when a person avoids a stressor (eg, 'I try not to think about the problem'), measured by using the Coping Strategies Inventory Short Form, were associated with significantly higher CBR levels. Disorder may also be related to physical activity. Our disorder marker included condition of the streets, which may impact even utilitarian physical activity ${ }^{7374}$ and thereby CBR levels. Furthermore, our marker of neighbourhood disorder included air quality, which may also directly impact CBR, through the immune/inflammatory system. ${ }^{75}$ However, our literature review has not revealed evidence supporting greater exposure of women versus men to poorer air quality in residential environments. Future behavioural studies exploring similar associations may help identify additional covariates which can inform sex-specific interventions for reducing CBR among Jamaicans. Our finding that greater neighbourhood disorder was significantly associated with high CBR for women but not men may reflect neighbourhood disorder serving as a proxy for neighbourhood SES.$^{45}$ While this finding aligns with a few others on poorer women's susceptibility to repeated exposures and adaptations to stressors in more developed country contexts, ${ }^{413} 76$ similar scholarship on CBR in developing contexts such as the Caribbean is limited.

There are strengths and potential limitations of this study. Strengths include the fact that this is the first study to demonstrate sex differences in CBR in a small island developing country, and the first to examine neighbourhood influences including factors beyond socioeconomic status, on biological stress in a middle-income country context. In addition, this study provided a large sample size representative of Jamaicans aged 15-74 years. Utilisation of a multilevel approach and examination of cumulative biological risk in this context is another strength. On the other hand, there are a number of potential limitations. First, cross-sectional data were used which limits our ability to make inferences regarding causation or say definitively whether our findings show age trends. It also may not be possible to generalise our results to other Black populations. Second, we are also unclear if the observed sex differential reflects genetic, environmental and/or gender underpinnings unique to the Jamaican context, or simply differences with unmeasured sample characteristics. For example, our results suggest an independent effect for cumulative biological risk neighbourhood disorder-level context in women, but not for men. However, the analysis lacked sex-specific individual level data such as sex-specific exposure and physiological and/or neuro-hormonal changes. Individual-level socioeconomic status effects could be more apparent than aggregate neighbourhood disorders or at the very least that they would provide independent or confounded impacts for cumulative biological risk. Additionally, there is no agreed gold standard for the operationalisation of CBR or AL. For example, our study included only seven markers compared with others that used between nine and 11 biomarkers. ${ }^{776}$ In particular, as stated previously we had no individual-level neuroendocrine or immune biomarkers and may have missed other important associations. Of note, studies in Jamaica have documented a strong association between morning salivary cortisol levels and hypertension in mothers and their offspring. ${ }^{62}$ Additionally, the neighbourhood was defined as an ED, many of which are heterogeneous. It is quite possible that important geographic effects may have been misclassified or not captured. Neighbourhood characteristics were subjectively assessed by interviewers, increasing the possibility of information bias. We also had no information on the inter-rater reliability of neighbourhood assessments, given the existing nature of the data and time frame since data collection. While we assume, given the information on training of interviewer perceptions, that the reliability was high, there was no way to test this.

Targeting neighbourhood change is feasible and may not only improve neighbourhood quality but also exert a small, sustained improvement in the health of women in those neighbourhoods. From a public health perspective, such structural changes offer an effective alternative method for reducing health disparities. In Jamaica we have found significant clustering at the neighbourhood level in obesity and significant increase in obesity among women in the absence of supermarkets and markets, suggesting the need for greater emphasis on policies, programmes and interventions that are focused on the neighbourhood-level effects. ${ }^{77}$ This study delves even deeper, considering potential biological impacts that may occur irrespective of women's individual behaviours, and suggests policy-makers and clinicians implement programmes focusing on earlier monitoring of biological stress before NCDs develop. 
The results from this study also strengthen the case for multidisciplinary local and regional health research that is sensitive to sex differences in exposures and vulnerabilities that likely contribute to CBR differences and related health outcomes such as NCDs. The higher CBR score among women in tandem with the higher ICC levels for the women versus men by EDs, suggests that gender specific factors must be considered in the development of a programme of research on CBR in the Jamaican health context. ${ }^{45}$ The sex differences in CBR clustering by ED also suggests the need for multilevel models that address the possible gendered vulnerabilities and exposures within the context of objective measurements of neighbourhood disorder and other neighbourhood level factors.

\section{Author affiliations}

${ }^{1}$ Department of Community Health and Psychiatry, University of the West Indies, Mona, Jamaica

${ }^{2}$ Louisiana Department of Health, Office of Public Health, Bureau of Family Health, Baton Rouge, Louisiana, USA

${ }^{3}$ Caribbean Institute for Health Research, University of the West Indies, Mona, Jamaica

${ }^{4}$ Mona Geolnformatics Institute, University of the West Indies, Mona, Jamaica ${ }^{5}$ Department of Global Community Health and Behavioral Sciences, School of Public Health and Tropical Medicine, Tulane University, New Orleans, Louisiana, USA

Contributors CAC-M, IG and KPT conceived the study. LG and PL-A geocoded the data. CAC-M, EM, KPT, and NOY analysed the data. CAC-M wrote the manuscript. MKT-R, SM, DF, GG-S, RW and KPT edited the paper. All authors approved the final manuscript.

Funding The JHLS II was supported by the National Health Fund, Jamaica.

Competing interests None declared.

Patient consent Not required.

Ethics approval The JHLS II was approved by the Ministry of Health, Jamaica and the University Hospital of the West Indies. No additional ethical approval was necessary for this secondary data analysis.

Provenance and peer review Not commissioned; externally peer reviewed. Data sharing statement No additional data are provided.

Open access This is an open access article distributed in accordance with the Creative Commons Attribution Non Commercial (CC BY-NC 4.0) license, which permits others to distribute, remix, adapt, build upon this work non-commercially, and license their derivative works on different terms, provided the original work is properly cited, appropriate credit is given, any changes made indicated, and the use is non-commercial. See: http://creativecommons.org/licenses/by-nc/4.0/.

\section{REFERENCES}

1. Beaglehole R, Bonita R, Horton R, et al. Priority actions for the noncommunicable disease crisis. Lancet 2011;377:1438-47.

2. McEwen BS, Stellar E. Stress and the individual. Mechanisms leading to disease. Arch Intern Med 1993;153:2093-101.

3. McEwen BS. Protective and damaging effects of stress mediators. $N$ Engl J Med 1998;338:171-9.

4. Geronimus AT, Hicken M, Keene D, et al. "Weathering" and age patterns of allostatic load scores among blacks and whites in the United States. Am J Public Health 2006;96:826-33.

5. Borrell LN, Dallo FJ, Nguyen N. Racial/ethnic disparities in all-cause mortality in U.S. adults: the effect of allostatic load. Public Health Rep 2010;125:810-6.

6. Seeman TE, Singer BH, Rowe JW, et al. Price of adaptation-allostatic load and its health consequences. MacArthur studies of successful aging. Arch Intern Med 1997;157:2259-68.

7. Beckie TM. A systematic review of allostatic load, health, and health disparities. Biol Res Nurs 2012;14:311-46.
8. McEwen BS, Seeman T. Protective and damaging effects of mediators of stress. Elaborating and testing the concepts of allostasis and allostatic load. Ann N Y Acad Sci 1999;896:30-47.

9. Seeman TE, McEwen BS. Social environment characteristics and neuroendocrine function: the impact of social ties and support on neuroendocrine regulation. Psychosom Med 1996;58:459-71.

10. Bird CE, Seeman T, Escarce JJ, et al. Neighbourhood socioeconomic status and biological 'wear and tear' in a nationally representative sample of US adults. J Epidemiol Community Health 2010;64:860-5.

11. King KE, Morenoff JD, House JS. Neighborhood context and social disparities in cumulative biological risk factors. Psychosom Med 2011;73:572-9.

12. Schulz AJ, Mentz G, Lachance L, et al. Associations between socioeconomic status and allostatic load: effects of neighborhood poverty and tests of mediating pathways. Am J Public Health 2012;102:1706-14.

13. Merkin SS, Basurto-Dávila R, Karlamangla A, et al. Neighborhoods and cumulative biological risk profiles by race/ethnicity in a national sample of U.S. adults: NHANES III. Ann Epidemiol 2009;19:194-201.

14. Robinson Al, Carnes F, Oreskovic NM. Spatial analysis of crime incidence and adolescent physical activity. Prev Med 2016;85:74-7.

15. Sallis JF, Bowles HR, Bauman A, et al. Neighborhood environments and physical activity among adults in 11 countries. Am J Prev Med 2009;36:484-90.

16. Swinburn B, Egger G, Raza F. Dissecting obesogenic environments: the development and application of a framework for identifying and prioritizing environmental interventions for obesity. Prev Med 1999;29(6 Pt 1):563-70.

17. Gordon-Larsen $\mathrm{P}$, Nelson MC, Page P, et al. Inequality in the built environment underlies key health disparities in physical activity and obesity. Pediatrics 2006;117:417-24.

18. Ross CE, Mirowsky J. Neighborhood disadvantage, disorder, and health. J Health Soc Behav 2001;42:258-76.

19. Theall KP, Brett ZH, Shirtcliff EA, et al. Neighborhood disorder and telomeres: connecting children's exposure to community level stress and cellular response. Soc Sci Med 2013;85:50-8.

20. Hosseini F, Adha N, Zainol R, et al. Neighborhood-level stress and circadian cortisol: a systematic review and meta-analysis. Iran J Public Health 2014;43:1324-34.

21. Stafford M, Cummins S, Ellaway A, et al. Pathways to obesity: identifying local, modifiable determinants of physical activity and diet. Soc Sci Med 2007;65:1882-97.

22. Harrington DW, Elliott SJ. Weighing the importance of neighbourhood: a multilevel exploration of the determinants of overweight and obesity. Soc Sci Med 2009;68:593-600.

23. Diez Roux AV, Mujahid MS, Hirsch JA, et al. The impact of neighborhoods on CV risk. Glob Heart 2016;11:353-63.

24. Yang Y, Kozloski M. Sex differences in age trajectories of physiological dysregulation: inflammation, metabolic syndrome, and allostatic load. J Gerontol A Biol Sci Med Sci 2011;66:493-500.

25. Kusano Y, Crews DE, Iwamoto A, et al. Allostatic load differs by sex and diet, but not age in older Japanese from the Goto Islands. Ann Hum Biol 2015:1-8.

26. Juster RP, Lupien S. A sex- and gender-based analysis of allostatic load and physical complaints. Gend Med 2012;9:511-23.

27. Lloyd-Jones DM, Wilson PW, Larson MG, et al. Framingham risk score and prediction of lifetime risk for coronary heart disease. Am J Cardiol 2004;94:20-4.

28. Eskes T, Haanen C. Why do women live longer than men? Eur J Obstet Gynecol Reprod Biol 2007;133:126-33.

29. Schuurs $A H$, Verheul HA. Effects of gender and sex steroids on the immune response. J Steroid Biochem 1990;35:157-72.

30. Stafford M, Cummins S, Macintyre S, et al. Gender differences in the associations between health and neighbourhood environment. Soc Sci Med 2005;60:1681-92.

31. Barnett R, Biener L, Baruch G. Gender and stress: The Free Press, 1987.

32. Bebbington P, Dunn G, Jenkins R, et al. The influence of age and sex on the prevalence of depressive conditions: report from the National Survey of Psychiatric Morbidity. Int Rev Psychiatry 2003;15:74-83.

33. Kessler RC, Brown RL, Broman CL. Sex differences in psychiatric help-seeking: evidence from four large-scale surveys. J Health Soc Behav 1981;22:49-64.

34. Kessler RC, McLeod JD. Sex differences in vulnerability to undesirable life events. Am Sociol Rev 1984;49:620-31.

35. LaVeist TA, Wallace JM. Health risk and inequitable distribution of liquor stores in African American neighborhood. Soc Sci Med 2000;51:613-7.

36. Lean ME, Han TS, Morrison CE. Waist circumference as a measure for indicating need for weight management. BMJ 1995;311:158-61. 
37. Theall KP, Drury SS, Shirtcliff EA. Cumulative neighborhood risk of psychosocial stress and allostatic load in adolescents. Am J Epidemiol 2012;176(Suppl 7):S164-74.

38. Chum A, O'Campo P. Cross-sectional associations between residential environmental exposures and cardiovascular diseases. BMC Public Health 2015;15:438.

39. Wilks R, Younger N, Tulloch-Reid M, et al. Jamaica Health and Lifestyle Survey 2007-8. http://www.mona.uwi.edu/reports/health/ JHLSII_final_may09.pdf

40. Abdulkadri $\bar{A}$, Cunningham-Myrie C, Forrester T. Economic burden of diabetes and hypertension in CARICOM states. Soc Econ Stud 2009;58:175-97.

41. Hospedales CJ, Samuels TA, Cummings R, et al. Raising the priority of chronic noncommunicable diseases in the Caribbean. Rev Panam Salud Publica 2011;30:393-400.

42. Statistical Institute of Jamaica. 2015 http://statinja.gov.jm/living conditions_poverty.aspx (accessed June 15, 2018).

43. Austin-Broos D. Urban life in Kingston Jamaica: the culture and class ideology of two neighborhoods: Routledge, 2017.

44. Lowe GA, Lipps G, Gibson RC, et al. Neighbourhood factors and depression among adolescents in four Caribbean countries. PLoS One 2014;9:e95538.

45. Mullings JA, McCaw-Binns AM, Archer C, et al. Gender differences in the effects of urban neighborhood on depressive symptoms in Jamaica. Rev Panam Salud Publica 2013;34:385-92.

46. Cunningham-Myrie CA, Theall KP, Younger NO, et al. Associations between neighborhood effects and physical activity, obesity, and diabetes: The Jamaica Health and Lifestyle Survey 2008. J Clin Epidemiol 2015;68:970-8.

47. Bernard P, Charafeddine R, Frohlich $\mathrm{KL}$, et al. Health inequalities and place: a theoretical conception of neighbourhood. Soc Sci Med 2007;65:1839-52.

48. Sampson R, Morenoff J. Janelle D, ed. Spatial (Dis)Advantage and Homicide in Chicago Neighborhoods, in Spatially Integrated Social Science, M: Oxford: New York, NY, 2004:145-70.

49. Krieger N. Methods for the scientific study of discrimination and health: an ecosocial approach. Am J Public Health 2012;102:936-44.

50. Barnes PJ. Immunology of asthma and chronic obstructive pulmonary disease. Nat Rev Immunol 2008;8:183-92.

51. Roth GA, Finn SD, Mokdad AH, et al. High total serum cholesterol, medication coverage and therapeutic control: an analysis of national health examination survey data from eight countries. Bull World Health Organ 2011;89:92-101.

52. World Health Organization. Definition and diagnosis of diabetes mellitus and intermediate hyperglycaemia: report of a WHO/IDF Consultation Report. Geneva: World Health Organization, 2006.

53. Koebnick C, Black MH, Wu J, et al. High blood pressure in overweight and obese youth: implications for screening. J Clin Hypertens 2013;15:793-805.

54. Sampson RJ, Raudenbush SW. Systematic social observation of public spaces: a new look at disorder in urban neighborhoods. Am J Sociol 1999;105:603-51.

55. Odgers CL, Caspi A, Bates CJ, et al. Systematic social observation of children's neighborhoods using Google Street View: a reliable and cost-effective method. J Child Psychol Psychiatry 2012;53:1009-17.

56. Ross CE, Jang SJ. Neighborhood disorder, fear, and mistrust: the buffering role of social ties with neighbors. Am J Community Psychol 2000;28:401-20.

57. Sampson RJ, Raudenbush SW. Seeing disorder: neighborhood stigma and the social construction of "broken windows". Soc Psychol Q 2004;67:319-42.

58. Duneier M. Sidewalk: Macmillan, 1999.
59. Harcourt BE. Illusion of order: The false promise of broken windows policing: Harvard University Press, 2009.

60. Raudenbush SW, Bryk AS. Hierarchical linear models: applications and data analysis methods: Sage Publications, Incorporated, 2001:1.

61. Snijders TAB, Bosker RJ. Multilevel analysis: an introduction to basic and advanced multilevel modeling. Thousand Oaks, Calif.; London: SAGE, 1999

62. Merlo J, Chaix B, Ohlsson $\mathrm{H}$, et al. A brief conceptual tutorial of multilevel analysis in social epidemiology: using measures of clustering in multilevel logistic regression to investigate contextual phenomena. J Epidemiol Community Health 2006;60:290-7.

63. Crimmins EM, Johnston M, Hayward M, et al. Age differences in allostatic load: an index of physiological dysregulation. Exp Gerontol 2003;38:731-4.

64. Mair CA, Cutchin MP, Kristen Peek M. Allostatic load in an environmental riskscape: the role of stressors and gender. Health Place 2011;17:978-87.

65. Boyne MS, Woollard A, Phillips DI, et al. The association of hypothalamic-pituitary-adrenal axis activity and blood pressure in an Afro-Caribbean population. Psychoneuroendocrinology 2009;34:736-42.

66. Chong RY, Uhart M, McCaul ME, et al. Whites have a more robust hypothalamic-pituitary-adrenal axis response to a psychological stressor than blacks. Psychoneuroendocrinology 2008;33:246-54.

67. Stigsdotter UK, Ekholm O, Schipperijn J, et al. Health promoting outdoor environments--associations between green space, and health, health-related quality of life and stress based on a Danish national representative survey. Scand J Public Health 2010;38:411-7.

68. Richardson EA, Pearce J, Mitchell R, et al. Role of physical activity in the relationship between urban green space and health. Public Health 2013;127:318-24.

69. Ord K, Mitchell R, Pearce J. Is level of neighbourhood green space associated with physical activity in green space? Int J Behav Nutr Phys Act 2013;10:127.

70. Bower KM, Thorpe RJ, Rohde C, et al. The intersection of neighborhood racial segregation, poverty, and urbanicity and its impact on food store availability in the United States. Prev Med 2014;58:33-9.

71. Moore LV, Diez Roux AV. Associations of neighborhood characteristics with the location and type of food stores. Am J Public Health 2006;96:325-31.

72. Fernandez CA, Loucks EB, Arheart KL, et al. Evaluating the effects of coping style on allostatic load, by sex: the Jackson heart study, 2000-2004. Prev Chronic Dis 2015;12:E165.

73. Lee C, Ory MG, Yoon J, et al. Neighborhood walking among overweight and obese adults: age variations in barriers and motivators. J Community Health 2013;38:12-22.

74. Miles R, Panton LB, Jang M, et al. Residential context, walking and obesity: two African-American neighborhoods compared. Health Place 2008;14:275-86.

75. Clougherty JE, Kubzansky LD. A framework for examining social stress and susceptibility to air pollution in respiratory health. Environ Health Perspect 2009;117:1351-8.

76. Hickson DA, Diez Roux AV, Gebreab SY, et al. Social patterning of cumulative biological risk by education and income among African Americans. Am J Public Health 2012;102:1362-9.

77. Myrie CA. An Exploration of Geographic Variation in Obesity, Its Key Risk Factors and Comorbidities. Are There Opportunities for Tailoring Public Health Interventions? Secondary Analysis of The Jamaica Health and Lifestyle Survey 2008 (JHLS II) [dissertation]. Mona, Jamaica: University of the West Indies, 2018:371. 